\title{
Memory and Temporal Perspective: The Role of Temporal Frameworks in Memory Development
}

\author{
Teresa McCormack
}

University of Warwick, United Kingdom

and

\section{Christoph Hoerl}

Department of Philosophy, University of Warwick, United Kingdom

\begin{abstract}
An account of the development of temporal understanding is proposed which links such understanding with the development of episodic memory. We distinguish between different ways of representing time in terms of the kinds of temporal frameworks they involve. Distinctions are made between frameworks that are perspectival or nonperspectival and those that represent recurrent sequences or particular times. Even primitive temporal understanding integrates both perspectival and nonperspectival components. However, since early frameworks are event-based and localized, they are not yet sufficient for episodic memory in that they do not enable the child to think of events as having occurred at particular points in time. We describe the emergence of new kinds of frameworks in terms of the development of temporal decentering. Two levels of temporal decentering are distinguished, with the higher level involving an appreciation of how event representations depend on one's temporal perspective. (๑) 1999 Academic Press
\end{abstract}

The aim of this paper is to give an account of the development of temporal understanding by detailing the different kinds of representational frameworks used in children's reasoning about time at different developmental

This research was supported by a grant from the Medical Research Council (G9608199) to the first author and an Institutional Fellowship from the British Academy Humanities Research Board awarded to the second author. Many of the ideas expressed here have emerged in the context of the Time and Memory seminar series held by the Warwick HRB Interdisciplinary Project on Consciousness and Self-Consciousness. We thank the speakers in that series and the members of the Project for their input, in particular Naomi Eilan and John Campbell. We are also grateful to Chris Peacocke, Sue Leekam, William Friedman, Robyn Fivush, and Mark Howe for their helpful comments on an earlier draft.

Address correspondence and reprint requests to Teresa McCormack, Department of Psychology, University of Warwick, Coventry, UK, CV4 7AL. E-mail: T.McCormack@warwick.ac.uk. 
stages. Giving such an account is important since we believe that the development of episodic memory depends upon the acquisition of a specific kind of temporal understanding, namely, possession of the concept of particular past times. There are four sections to the paper. The first briefly discusses accounts of episodic memory and their developmental implications. It is argued that developmentalists have overlooked the fact that the ability to think of particular, unique times is a defining feature of episodic memory. Defining episodic memory in this way helps articulate what underpins some of our intuitions about what is measured by various kinds of memory tasks. If this definition is correct, then a full account of memory development should explain how developing temporal understanding enables new ways of remembering information. However, as yet there are few detailed accounts of how the ability to represent and conceptualize time develops (see Nelson, 1996, for this point).

As developmentalists, we need to ask "What other, more primitive, ways of representing time may there be, other than the ways we as adults have?" In the second and third sections, existing psychological accounts of temporal representation, together with distinctions philosophers have made between different ways of ordering events in time, are used to set out different frameworks for representing the temporal location of events. The first key distinction is between frameworks that are intrinsically perspectival and ones which are not, and a second important distinction is between frameworks that locate events with respect to recurrent temporal features and frameworks that assign events unique locations in time.

In the last section, the notion of temporal decentering is used to capture the nature of mature representational abilities involved in episodic memory. The ability to temporally decenter is the ability to consider alternative temporal perspectives on events and to understand the relationship of these perspectives to one's current perspective. We distinguish between two different levels of temporal decentering, one of which involves possession of the concept of a temporally extended self (Povinelli, Landau, \& Perilloux, 1996).

\section{EPISODIC MEMORY}

\section{Definitions of Episodic Memory}

The concept of episodic memory has heavily influenced long-term memory research over the last two decades, although the interpretation of the term has undergone significant changes. The concept was originally introduced to describe a specialized memory subsystem for receiving and storing a particular kind of information, namely, "information about temporally dated episodes or events, and temporal-spatial relations among these events" (Tulving, 1972, p. 385). Tulving's further claim that these episodes or events are stored in terms of their "autobiographical reference" to other contents of episodic memory had less influence on empirical and neuropsychological 
research, and, typically, episodic memory has been examined using tasks which require recognition or recall of word lists rather than tasks involving personal life events.

Thus, many psychologists have assumed that what is distinctive about episodic memory is that it involves retrieval of events along with contextual information. However, the nature of such information is not clear: In particular, this information cannot plausibly be the temporal dates of events, given what is known about temporal encoding processes in long-term memory. Although some researchers have claimed that the dates or times of all events are tagged automatically (Hasher \& Zacks, 1979; Zacks, Hasher, Alba, Sanft, \& Rose, 1984), there is little supportive evidence for the existence of such a coding process, at least outside the range of short-term memory. In laboratory tasks, encoding and retrieving temporal information is an effortful process (Naveh-Benjamin, 1990), and judgments of temporal location may be made inferentially on the basis of nontemporal information (Hintzman, Block, \& Summers, 1973; Guenther \& Linton, 1975). In studies on memory for life-events, exact dates are rarely retrieved (e.g., Burt, 1992; Friedman, 1987), and dates are poor retrieval cues (Wagenaar, 1986). It appears that if temporal information is encoded at all, it is easily forgotten, even when memory for other aspects of events is intact (Friedman, 1993). In the light of such findings, it is clear that the term episodic memory cannot be restricted to temporally dated memories. In practice, the term tends to be used for event memories which are assumed to include some, usually unspecified, kind of contextual information (see Davies \& Thomson, 1988, for discussion of context in memory).

Indeed, in his own work, Tulving has increasingly stressed the selfreferential or self-conscious component of episodic memory, rather than the information it involves (Tulving, 1983, 1985). This is particularly clear in Wheeler, Stuss, and Tulving's (1997) recent theoretical account of episodic memory and frontal functioning, in which episodic memory is discussed in terms of the particular kind of experience or awareness associated with it. Episodic memory is described in terms of the involvement of a specific capacity for self-conscious reasoning defined as autonoetic consciousness, or "the ability to mentally represent and become aware of [one's] experiences in subjective time"' (p. 349). This is contrasted with the noetic awareness which accompanies semantic memories that involve knowledge retrieval but not the reexperiencing of one's personal past. In fact, Wheeler et al. explicitly reject the idea that episodic memory is a specialized subsystem which stores particular kinds of contextual information: "Virtually any category of information can be, in principle, represented in and its retrieval mediated by, semantic memory, including knowledge of source and contextual information. . . To tap into autonoetic consciousness, a test must require a rememberer to contemplate some past personal event directly as it was subjectively experienced.', (p. 338). 
There has been considerable debate over whether young children or infants can be said to have episodic memory, particularly in the light of the results of studies employing new methodologies, such as deferred imitation or reinforcement techniques (Bauer \& Mandler, 1989, 1992; Meltzoff, 1990; Rovee-Collier, 1997). Numerous deferred imitations studies have shown that infants can reproduce an action sequence of up to four elements that they have observed an adult perform on a single occasion, even after a delay of two weeks (see Bauer, 1995, for review). Whether one wants to describe such early memory abilities as episodic memory depends, of course, upon the definition given of episodic memory. In particular, the claim that such memory is self-conscious has been thought to have important developmental implications. Perner (1990, 1991, in press) has pointed out that this selfconsciousness can be thought of as a particular kind of theory of mind understanding. He has argued that below four years, children lack the conception of mental states necessary to think of their past experiences as the origins of their memories. Thus, the suggestion is that children of this age do not have autonoetic consciousness, and, hence, do not have episodic memory. This, Perner has argued (Perner \& Ruffman, 1995), can also explain the phenomenon of childhood amnesia, the inability of adults to remember very early childhood events (Kihlstrom \& Harackiewicz, 1982; Wetzler \& Sweeny, 1986).

\section{Episodic Memory and the Concept of Particular Times}

The description of episodic memory as involving a self-conscious activity has interesting developmental implications. However, we believe that it is important not to overlook a different aspect of such memories, an aspect which is implicit in Tulving's (1972) original description. Although it may have been misleading to describe episodic memories as "temporally dated," episodic memories do seem to involve a special way of thinking about time. Specifically, such memories involve thinking of events as having occurred at particular, unique times. This characteristic of episodic memories has received less attention, but it is clearly also of special relevance from a developmental perspective, since it may be asked when this kind of thought becomes available to young children. The mature thinker is obviously capable of thinking of events as having happened at particular times: Even under circumstances in which a type of event occurs repeatedly (e.g., traveling to work every day), adults are able to consider individual, temporally distinct, occurrences of the event and indeed to think about their temporal relations to each other. We view representing an event as having happened at a particular time in the past as a defining characteristic of episodic memory. Our claim is that young children do not have the concept of particular times, the concept which enables one to distinguish between any given occurrence of an event and other occurrences of similar events at other times.

In focusing on this aspect of episodic memory, the aim is not to revive 
the idea that episodic memories are always temporally dated or involve the retrieval of precise temporal information. As mentioned above, even as adults, we often remember events but have difficulty judging when they occurred. However, when this happens to us, we still believe there is a fact of the matter as to at what particular time the event occurred. Indeed, we often try to work out this particular temporal location, for example by making inferences using other contextual information (e.g., what the weather was like, who was there, etc.). Young children's understanding of time does not allow them to grasp that, for any event, there is such a particular, unique temporal location.

Although the suggestion that young children do not have a concept of particular times and, therefore, do not have episodic memory, has not been made explicit in the literature, similar intuitions seem to have influenced others' interpretations of early memory abilities. For example, Perner (in press), in his discussion of deferred imitation, pointed out that "delayed imitation that is based on a single event . . . should not be equated with a memory (knowledge) of that event as [italics added] a single past event." While deferred imitation tasks show that young children may be able to include temporal information in their representations of action sequences in the sense of being able to retain information about the temporal sequence in which elements occur, this information may be generic, rather than eventspecific. Generic information here means information about a temporal structure numerically different event sequences may have and which, therefore, does not distinguish between one event sequence and another. Even if a child is recalling information acquired in a single episode, this information may still be generic. As will be discussed below, the question as to whether a child has genuine episodic memories can be raised even if she is responding verbally using past tense morphology. In this case, an attribution of episodic memory still depends upon a consideration of the type of temporal understanding subserving her use of the past tense.

Few memory theorists would disagree with the basic distinction between episodic and generic memory, and indeed, much research on children's memory narratives has been aimed at disentangling recall of specific past episodes from recall of scripts (e.g., Farrar \& Goodman, 1990). However, we believe that for this distinction to be meaningful, it is necessary to give a developmental account of the particular kinds of temporal understanding which allow the child to single out the remembered event as a unique occurrence. At the moment, there is little work in psychology which distinguishes between different kinds of temporal understanding, and existing work on the developmental psychology of time has not tended to address this kind of issue. Thus, this paper aims to provide a new developmental account of temporal understanding by drawing on existing work on memory and language development, together with general considerations from the philosophy of time and memory. 


\section{Temporal Frameworks}

In what follows, the notion of temporal frameworks will be employed in providing a developmental account of temporal understanding. The notion of a framework or frame of reference has been used extensively in the field of spatial cognition (Eilan, McCarthy, \& Brewer, 1993). The spatial location of an object can be specified in many different ways, such as "to the right" or "by the table" or at a given degree of longitude and latitude. To talk about different frameworks here is a way of capturing what, for example, is in common between all representations of places involving terms such as "to the right" and "to the left" and how they differ, say, from representations of places specified in terms of longitude and latitude. In each case, a different kind of framework is involved. Similarly, different kinds of frameworks may be involved in specifying the temporal location of an event: For example, an event could be described as occurring on a given date, or at a particular time of day, or as so many days from the present, or as occurring before or after another landmark event, and so on.

A framework is involved in someone's reasoning whenever they have a representation of a domain that can be used to integrate information about the locations of objects or events in this domain. Orienting oneself in a domain (Friedman, 1990), i.e., determining one's own position relative to other objects or events in the domain, requires a framework, as does determining the relative locations which objects or events in a domain occupy with respect to each other, independently of where oneself is located. Having a framework does not necessarily require that for any two objects or events one is actually able to determine their relative locations. Frameworks can be localized. That is to say, they may allow one to determine locations with respect to some objects or events, but not with respect to others. What is crucial to a framework, however, is that it has a certain amount of flexibility. A framework is not just a representation of the relative locations of individual objects or events; it must also allow one to determine one's own location relative to at least some of these objects or events, even if one's location varies. Or it must allow the location of newly encountered objects or events to be determined with respect to the location of at least some objects or events one already knows about. In the following sections, different kinds of temporal frameworks will be described and used to give an account of the development of temporal understanding. We hope that, in describing the ways in which frameworks can vary, some developmentally primitive ways of representing time can be captured.

\section{PERSPECTIVAL AND NONPERSPECTIVAL REPRESENTATION OF TIMES}

Theories of spatial representation often make a distinction between egocentric, or perspectival, and allocentric, or nonperspectival, representations 
of space (O'Keefe \& Nadel, 1978; Pick \& Lockman, 1981). A perspectival representation, in this sense, is one which locates entities in a framework which depends on one's own spatial position, whereas a nonperspectival representation locates entities in a framework which is independent of one's own spatial position. Philosophers, following McTaggart (1927), have drawn a similar distinction between two ways of ordering events in time. The socalled A-series is the series of positions running from the past, through the present, to the future. Typical linguistic counterparts of A-series determinations are terms such as "now," "yesterday," and "in a short while," the correct use of which depends on when they are uttered. Assigning an event a position in the A-series depends on one's own position in time. The Aseries can thus be seen as a framework for perspectival temporal representations which locate events in virtue of the temporal relations in which one stands to them. This is different from assigning an event a position in the so-called B-series, the series running from earlier to later. The correct use of the linguistic counterparts of B-series determinations - terms such as "before' and "after' or dates — does not depend on when they are uttered. An event can be described as happening before or after another event, or both events can be described as happening on certain dates, independently of where in time one is located relative to them. In contrast to the A-series, the B-series can thus be seen as a framework for nonperspectival temporal representations.

For developmentalists, the distinction between perspectival and nonperspectival temporal frameworks raises a number of important issues. In particular, it may be asked whether the two frameworks develop independently of each other, whether one of them is developmentally prior, and when they become integrated to give a mature understanding of time. However, the difficult empirical issue is inferring the nature of children's temporal frameworks from particular kinds of behavior. Unlike in the case of spatial representations, where grasp of particular spatial relationships can be manifested in spatial behavior-e.g., in object retrieval or spatial navigation-it is unclear what kinds of behavior would manifest possession of particular kinds of temporal frameworks. Existing empirical research which seems to have the most bearing on these issues lies in the field of language acquisition, particularly work on the acquisition of tense and temporal terms.

\section{Nonperspectival Temporal Frameworks: Scripts}

An influential and intuitively plausible claim that has emerged from developmental work on spatial representation holds that perspectival frameworks are developmentally prior to nonperspectival frameworks. This claim has its origins in the Piagetian framework, in which many of the young child's cognitive limitations are described in terms of egocentrism of thought. However, it is not clear that intuitively we might want to make the same claims about developmental priority when it comes to temporal frameworks. In fact, it 
may seem more plausible to claim that, in the case of temporal frameworks, nonperspectival frameworks develop first. One way in which this claim could be framed is in terms of the developmental priority of scriptlike knowledge over thought about past and future events. A script can be thought of as nonperspectival insofar as it is a representation of what normally happens: Scripts are usually told in the timeless present tense, and they typically concern recurrent features in a child's life such as seeing a doctor, going to a birthday party, or eating in a fast-food restaurant (Nelson, 1986; Schank \& Abelson, 1977).

Scripts function as frameworks in that they provide ways of representing the location of novel events in time. Thus, a child who has formed a script of a particular kind of sequence may be able to recognize a newly occurring sequence as falling under that script even if (a) it contains a new element, (b) one of its elements is substituted by a different element, or (c) one of the elements is missing. Such a child would be able to represent, say, an unexpected element encountered within the sequence as standing in a certain temporal relation to other elements in the sequence, and to code it as an option. Possession of script knowledge seems to require some ability to distinguish between the position within a series at which a certain event happens and the particular event that happens at this position. It is by being variable in this sense that scripts can be counted as providing a framework, although this may not be the case for, say, the representations involved in deferred imitation. Deferred imitation of action sequences may involve representations of a much simpler kind which may not allow for such variations to occur. With such representations of action sequences, the only way the child has of representing a new variant of a familiar sequence is by forming a completely new representation. In this case, sequences can only be represented as a whole with a fixed set of elements, and, therefore, the resulting representations cannot be said to provide a framework in which other elements could occur.

A considerable body of research has shown that children acquire scriptknowledge at a very early age and extract scripts after even a small number of experiences of an event sequence (e.g., Fivush, 1984; Hudson \& Nelson, 1986; Nelson, 1986; Nelson \& Hudson, 1988; Nelson \& Ross, 1980). This may suggest that scripts are good candidates for developmentally early nonperspectival representational frameworks. Script knowledge, while being based on past experience of the kinds of events mentioned in the script, does not seem to locate the events in a perspectival framework. When questioned about specific events, young children will tend to give a scriptlike account in reply, often in the present tense (Fivush \& Hamond, 1990). Scripts can be thought of as nonperspectival in the sense that they do not locate events with respect to the current point in time at which one is located. Rather, they describe the sequence of events relative to each other: In this sense, they are like the B-series. 
Nevertheless, there are theoretical considerations which may prevent concluding on the basis of early script use that nonperspectival frameworks are developmentally prior. It is at least arguable that use of scripts requires some form of perspectival representation. We have suggested that scripts may provide a way of locating events in a nonperspectival framework which codes their relation to other events which occur in a familiar sequence. However, the comparison with spatial representations indicates that we should generally be wary of thinking that nonperspectival representations, by themselves, could be sufficient for an understanding of the location of events in time (Friedman, 1990). Our grasp of space does not just depend on having nonperspectival knowledge (e.g., a cognitive map), but also on the way in which this knowledge can be put to use in the situation we are actually in. Maplike representations are only useful to us if we are able to determine which map depicts the current array, to determine the position on the map where we are currently located, and to track our movements on the map. In other words, grasp of spatial location depends on the ability to integrate nonperspectival with perspectival ways of thinking about the same space.

Similarly, a scriptlike representation will only be useful to a child who is able to recognize a present situation as falling under a script she already possesses and who is able to keep track of the successive stages of the sequence of events as they unfold. In other words, even using a script requires some grasp of one's current temporal location, and thus an ability to integrate the nonperspectival framework provided by the script with a perspectival framework. As will be shown below, there may be different ways in which such an integration may be achieved, and, correspondingly, different levels of sophistication in overall representational abilities. For the moment, it can be noted that, even though some perspectival representation is required to use a script, this perspectival knowledge may initially be quite primitive. In particular, while the acquisition of script knowledge may be based on a number of past experiences of occurrences of a sequence, the child's representational abilities may fall short of representing the relations between those different occurrences. This suggests that, early in development, children may be able to track their own position within a sequence, but are unable to locate the event sequence as a whole with respect to other occurrences of sequences of the same type (or, indeed, occurrences of other kinds of sequences).

\section{Perspectival Temporal Frameworks: The Aspect-Before-Tense Debate}

In the field of developmental psycholinguistics, several claims have been made about children's concepts of time based on their use of tensed forms of verbs and temporal terms. They can be seen as claims about the development of perspectival temporal frameworks, as shall now be shown. Using the correct tense of a verb shows a sensitivity to the relationship between the time the sentence is uttered (the speech time) and the time of the reported event (the event time), which may be different. As such, it indicates an ability 
on the part of the mature speaker to transcend the boundaries of the "here and now" of the speech context (Sachs, 1989), and to capture events happening at different times in their relation to his or her temporal perspective.

One of the most influential theories of tense is due to Reichenbach (1947). He recognized the existence of a third element in the mature speaker's use of tense which mediates between speech time and event time: reference time. Reichenbach saw reference time as a necessary ingredient of all tenses, but the role played by reference time can be made particularly clear by a consideration of the pluperfect. A sentence such as "Peter had gone" denotes a situation which lies at a time in the past, but this time is not as far back in the past as the event of Peter's leaving. Thus, the sentence introduces a time (reference time) which does not coincide with either speech time or event time. In order to understand the sentence, the hearer must consider a temporal perspective other than the present. In other words, the interpretation of a sentence like "Peter had gone" has to consider not only the speaker's actual vantage point, the speech time, but also another vantage point the speaker has in mind, the reference time, which lies after the time of the event of Peter's leaving but before the speech time.

Developmental accounts of the acquisition of tense have argued for various ways in which the representational abilities that underpin early use of tense morphology may be thought to fall short of the full-blown grasp of tense described by Reichenbach. One assumption commonly made in the literature is that children use tensed forms before they are able to engage in temporal decentering, i.e., before they are capable of forming the notion of other times as alternative temporal perspectives on which grasp of the idea of a reference time depends. What is more controversial is whether children who are thus unable to employ reference time in their uses of tensed forms can still be recognized as marking relations between speech time and event time, as mature users of tense do, or whether they must be seen as marking a completely different set of facts.

Thus, the defective tense hypothesis maintains that initial use of tense morphology does not actually involve reference to past, present, or future times at all: Rather, tense encodes aspectual features (see Bronckhart \& Sinclair, 1973, for an early expression of this claim). Aspect distinguishes between events not on the basis of the time at which they happen, as tense does, but on the basis of their internal temporal contour (Comrie, 1985). In English, for example, the contrast between "John is singing" and "John was singing" is one of tense (present vs past), whereas the distinction between "John was singing', and "John sang"' is one of aspect (continuing vs completed). The central claim of the defective tense hypothesis is that children initially produce the past tense to mark the completion of an event rather than to locate it in the past. Some studies (e.g., Antinucci \& Miller, 1976; Bloom, Lifter, \& Hafitz, 1980; Rispoli \& Bloom, 1985) had indicated that, at least until the age of 3 , use of past tense is limited to achievement and accomplishment 
verbs, which describe events with a definite point of completion (e.g., " drawing a circle," "winning the match"), whereas activity verbs (e.g., "swimming') are always used in the progressive tense (see Vendler, 1957, for this terminology). This has been taken to imply that "the children are focusing on the result of the event described by the verb ... As a result of the change denoted by a transitive verb, the object comes to be in a state; for example the action described by somebody broke the toy results in the state the toy is broken' (Antinucci \& Miller, 1976, p. 172). Since the child's thinking is restricted to the perspective of the present, she can consider past events only insofar as they manifest themselves in present results.

Several authors have disputed the existence of the kind of empirical evidence put forward by the defenders of the defective tense hypothesis. Specifically, it has been claimed that children, in fact, start using the past tense with activity verbs at the same time as they start using it with achievement and accomplishment verbs - toward the end of the second year (Smith, 1980; Smith \& Weist, 1987; Weist, 1989). It has, therefore, been argued that children at this stage have a primitive tense system which, like the adult system, is used to coordinate speech time and event time. We will call this the primitive tense hypothesis. According to this hypothesis, both the aspect and tense system are initially quite limited, because there is, as yet, no ability to use a reference time which might be different from the speech time. Thus, for example, children at this stage are not able to conceptualize events as ongoing-in-the-past and, therefore, to use the past progressive (Weist, 1986), and the use of tenses is restricted to marking the relation between event time and speech time simply in terms of simultaneity or sequence. Nevertheless, according to Smith (1980, p. 265), the primitive tense system "gives a precise meaning for pastness: pastness in the child's system indicates a time anterior to speech time.' This has been taken to imply that, before they are able to decenter in time, children already have a capacity for displacement: That is, an ability to locate events in the past, independently of whether these past events have resulted in a present, observable state or not. Crucially for present purposes, Weist (1989) has argued that it is the capacity for displacement which manifests possession of episodic memories.

The crucial difference between the defective tense hypothesis and the primitive tense hypothesis, as we have described them, lies in the kind of representations that children are claimed to be able to entertain before acquiring the capacity to decenter and to conceive of other times as affording different temporal perspectives. In order to count as drawing a genuine distinction between present and past, the child would need to have some way to represent events even though they are no longer going on. As Weist $(1989$, p. 69) points out: 'If, at this phase of development, 'out of sight' still meant 'out of mind,' there would be no representation to retrieve.' How the accounts differ is in terms of whether children at this stage are thought to represent past events as past events. However, although the accounts generate different 
empirical predictions, the empirical evidence seems far from decisive. We now wish to suggest that there is a different, theoretical consideration which an account of children's early perspectival temporal representations must meet.

Earlier, we discussed a certain form of nonperspectival representation which children may also be thought to possess before they acquire the ability to decenter in time, namely, scripts. We pointed out that scripts can only be put to use by a child who is able to integrate the nonperspectival information provided by the script with perspectival information. In other words, to put a script to use, the child must be able to keep track of where she is in the unfolding sequence instantiating the script. The nonperspectival information provided by the script must have a counterpart in the perspectival information available to the child as she executes the script. Script execution can, therefore, be seen as providing further evidence of the perspectival representational frameworks available to children before they can engage in temporal decentering, i.e., at the same developmental stage that we have been discussing with regard to children's early use of tense. This evidence, however, suggests that children's abilities to form perspectival temporal representations at this stage may be less limited than suggested by the defective tense hypothesis and more limited than suggested by the primitive tense hypothesis.

Saying that the nonperspectival information provided by the script must have a counterpart in the perspectival information available to the child as she executes the script means that the child must be able to represent elements of the to-be-executed script other than the one currently being executed. Thus, what we have here is precisely a case in which events in the sequence which are "out of sight," because they have already taken place or are as yet to happen, must not be "out of mind,"' or else the child would be unable to progress through the sequence determined by the script. Moreover, the child's ability to execute a script seems to entail that she can form perspectival representations of any kind of event that can occur in the script, not just those with observable consequences in the present, as the defective tense hypothesis suggests. Conversely, however, a child's ability to execute a script can provide evidence for perspectival representations only of those events that are part of the currently executed script, e.g., of events that happened earlier during a typical school day (Sachs, 1983). In the next section, we wish to show that this entails that the child may not yet have a notion of the particular times at which these events happen, since it may be unable to distinguish the present instantiation of the script from past or future ones. If this is true, it casts doubt on the claim made by proponents of the primitive tense hypothesis that children at this stage are already able to form episodic memories of events. This is because they may still lack the notion of the particular time when an event happened, which we take to be a necessary ingredient of a genuine episodic memory.

Where does this leave the question of whether children's initial use of 
tenses can be seen as marking the relation between speech time and event time, or whether they should be seen as marking aspectual features? We suggest that the most parsimonious account of children's representational abilities at this early stage, before they acquire the ability to decenter in time, is to interpret these abilities as a way of imposing aspectual features on events. In other words, children impose a perspective on the unfolding of events in as far as, at any given point in time, they classify some events as completed (even if they may not have a natural point of completion), using the past tense inflection, whereas they think of other events as ongoing. In this sense, aspectual distinctions do indeed influence the course of the acquisition of tense distinctions, though it is less clear whether one would still want to call such a use of tense markers "defective"' (see Bloom \& Harner, 1989, for a similar view). Moreover, this interpretation does not predict that children should initially be unable to form the past tense of activity verbs. Early use of tensed forms, according to this interpretation, is limited only in that it is event-based: It is based on children's experience with familiar event sequences, and the perspective it introduces is a perspective determined by their view on the status of events in those sequences, such as whether they are ongoing or completed. Others have already emphasized the role of scripts and event knowledge in the acquisition of new verbs (Aktar \& Tomasello, 1996; Tomasello \& Kruger, 1992). Here, we are claiming that such knowledge provides the foundation for early use of tensed forms (see Nelson, 1996, for a related claim). Since such early use is event-based, it does not supply the child with any means to think about the times at which the events in any given occurrence of the script happen that is independent of her following through the script.

\section{REPRESENTATION OF RECURRENT TEMPORAL FEATURES AND PARTICULAR TIMES}

Campbell (1994) has made a crucial distinction between what he has termed "temporal orientation with respect to phase", and "temporal orientation with respect to particular times." The former involves locating events with respect to the phase of a recurrent temporal sequence. There are many naturally occurring temporal sequences which are organized cyclically, which means that the end of one instantiation of the sequence coincides with the beginning of another: Examples are days, lunar cycles, and years. A considerable body of research has established that many animals, including humans, adjust their behavior to the state of such cycles. Other recurring temporal cycles with which we are familiar may be more arbitrary and can be thought of as social conventions, for example, weeks and months. Moreover, recurring sequences need not be cyclical in order for us to be able to adjust our behavior to their unfolding. We have already said that scripts represent familiar sequences that often occur many times (e.g., what happens at a visit to the doctor), although they do not necessarily recur at regular intervals. 
When recurrent sequences are used as a method of location, events are located with respect to the particular phase or state of the sequence at which they occur. So, for example, an event may be located with respect to the season of the year, the day of the week, or the point in the typical school day. However, locating an event in this way does not necessarily also involve locating it in any particular occurrence of that type of sequence: An event may be assigned a location, for example, in terms of the time of the day at which it occurs, without being assigned to any day in particular. Campbell (1994, p. 38) described this possibility as follows: "Consider an animal that hibernates. Through the part of the year for which it is awake, it regulates its activity depending on the season ... But it may not have the conception of the seasons as particular times; it may be incapable of differentiating between the autumn of one year and the autumn of another.' An event which is located only within a recurrent sequence is not though of as an episode. Indeed, if a creature is, say, unable to assign events to unique points in time, rather than merely to seasons in a year, we would not credit it with a proper grasp of the distinction between past, present, and future since it lacks the conceptual abilities to distinguish between the current year and others.

Campbell argued that the ability to locate events within recurrent sequences is more primitive in the evolutionary sense than the ability to locate events at particular points in time. The obvious issue is whether this is also the case with respect to human development. One possible approach to this question is to assume that representing recurrent sequences is the developmental primitive, and that representing particular times emerges with increasing sophistication in representing sequences (e.g., increasingly longer or more abstract recurrent sequences).

\section{Representing Recurrent Sequences}

In their characterization of sequential behavior, Brown and Vousden (1998) have argued that even relatively primitive organisms, such as insects, demonstrate temporally organized behaviors that can be thought of as internally generated. In line with Gallistel (1990), they suggested that oscillatorbased systems provide an animal with a way of being sensitive to the phase of various cycles. Oscillator systems function as timekeeping mechanisms and can be thought of as internal clocks. To provide useful functions, the internal clock system needs to be entrained by events in the world, by associating particular states of the internal clock with particular behaviors. For example, an animal may associate one particular food location with one time (i.e., state or phase of the oscillator system), a different location with a later time and so on, which enables it to turn up at a series of locations at the appropriate times of the day.

Clearly, temporally organized behavior and the representation of recurrent cycles even in young children is more sophisticated than in animals, although it is likely that much of the temporally organized behavior shown by human 
babies, such as feeding cycles, is similar to that described above and exploits similar mechanisms. Indeed, Brown and Vousden argued that human memory for sequences, such as recurrent sequences of events, has much in common with these more primitive kinds of animal behavior and relies on oscillator-based systems. However, they have also discussed ways in which the behavior of animals is limited and may differ from that of humans. Some of these ways are essentially quantitative, and can be thought of as "hardware" limitations in the oscillator system. Many animals are restricted in terms of the lengths of the periods of time to which they can adjust their behaviorbees, for example, do not seem to be able to entrain oscillators to periods greater than 24 hours. Humans are much more flexible in the lengths of periods of time that they are capable of representing.

Two further limitations are more qualitative in nature. Brown and Vousden point out that adult humans can decouple sequential behavior from the world, whereas this may not be the case for at least some animals. Animals, although capable of producing internally generated sequential behavior in the sense of not being reliant on external cues, have internal temporal representations which remain coupled to their environment. Human behavior, by contrast, is internally generated in a stronger sense. First, although some of our temporally organized behavior is entrained to external rhythms (e.g., daily or circadian rhythms), we also impose on our experience temporal structures which are more arbitrary. Further, we can decide to retrieve many behavioral sequences or representations of event sequences at will.

Another important way in which representations of recurrent sequences may become more sophisticated is in the extent to which they are organized hierarchically. For example, a representation of the series of events involved in a typical school day could also figure as a component of a representation of the typical school week, which could, in turn, figure in a component of a more extended period. Research on human memory for sequential information has shown that it does indeed have this hierarchical character, with temporal information about a given event being represented at numerous different levels of such a hierarchy (see Huttenlocher, Hedges, \& Prohaska, 1988, for evidence of hierarchical organization in autobiographical memory, and Nairne, 1991, for somewhat shorter-term memory). Thus, in adults, representations of recurrent event sequences are embedded in complex ways within other event sequences.

These considerations of the way in which representations of recurrent sequences become more sophisticated could be cast in developmental terms. First, development could involve a transition from externally to internally generated sequential behavior, with the retrieval or reinstatement of sequences coming under voluntary control. With development, representations of recurrent temporal sequences could become more arbitrary and flexible. Second, representations of recurrent sequences, such as what happens at a typical meal, during a day at nursery school, in a school week etc., could 
gradually acquire a hierarchical organization as children acquire increasingly abstract scripts within which other scripts could become embedded (Fivush, 1984; Ratner, Smith, \& Padgett, 1990).

\section{From Recurrent Sequences to Particular Times}

We now have a conception of how representations of recurrent sequences could become more sophisticated with development. Would possession of the kinds of cognitive resources we have described imply that a child is representing events as occurring at particular points in time? It is possible that even if a child has such resources, she may still fail to think of events as occurring at particular points in time. Even if they do form the developmental basis for a temporal framework which can represent particular times, more is needed to explain why mechanisms which were initially used to represent recurrent sequences are then put to work in this way. This is clear if we consider the limited function that temporal representations of recurrent sequences serves (see Campbell, 1994; Friedman, 1993).

For example, Katherine Nelson (1990, p. 308) has argued, "The most basic general function for memory ... is to provide guidance for action. What has happened is used as the basis for predicting what will come next. For this purpose the most useful type of evidence comes from events that are frequently repeated, and thus the most useful . . type of memory is that for familiar routine events, the type of generalized event memory realized as scripts." To fulfill this function, even memories that actually derive from individual episodes should not be represented as such, but as potentially reoccurring events. Indeed, the fact that children will extract scriptlike representations even after a single experience suggests that this often happens (Fivush, Hudson, \& Nelson, 1984).

The limitations of the practical understanding underlying these early representations of time may be made clearer if we consider how representations of space may be limited in an analogous way. One can imagine a primitive form of spatial reasoning which enables the child to think about the locations of two different objects within two different rooms without having any single way of locating the objects or understanding how the rooms are located relative to each other. The same could be true of early temporal frameworks: In the child's system, different events may be represented as part of two thematically unrelated recurrent sequences, and the child may not yet grasp the temporal relation between the events or the sequences in which they occur. Of course, as was suggested earlier, children's knowledge of recurrent sequences will gradually acquire a hierarchical organization such that the relationships between thematically related event sequences become represented. For example, the sequence of eating lunch at nursery school may become located within the higher-order sequence of the daily nursery school routine. However, there may still be no way of locating thematically unrelated sequences of events with each other. Indeed, many sequences of events 
do not have a consistent temporal relation with each other: For instance, visits to the doctor do not occur consistently on the same day of the week. When such relations are arbitrary, they do not have the kind of predictive value provided by representations of recurrent sequences.

Adults have quite different representations, such as the conventional clock and calendar system, which provide a single framework within which each event can be assigned a unique location, irrespective of its thematic relations to other events. But it is difficult to see how acquisition of such a framework could be the result of a mere increase in sophistication of representations of the kinds described so far, which rely on the fact that numerically different sequences of events can fall under the same representation. In the concluding section, we say more about this transition from representing recurrent sequences to representing particular times with regard to the kinds of decentering abilities involved, and thus the relation between the development of memory and self-consciousness.

\section{THE EMERGENCE OF EPISODIC MEMORY: TEMPORAL DECENTERING}

The basic distinctions between frameworks which are perspectival or nonperspectival and those which locate events with respect to recurrent temporal features or particular times have enabled us to put together a picture of how an understanding of time may develop from very basic ways of being responsive to temporal features of the environment. Findings from deferred imitation tasks indicate that early in development (within the first 18 months), infants have temporally organized representations of familiar action sequences and can acquire novel temporally ordered representations through observation. However, such representations may not yet be abstractions that can function as temporal frameworks - that is, they cannot be used to locate novel events. The earliest temporal frameworks make use of representations similar to those used in deferred imitation, in that they typically involve familiar event sequences. However, they are more abstract insofar as they allow variability in terms of what happens at any given occurrence of the event sequence. As such, they seem to require the ability to distinguish between the position in the sequence at which an event happens and the event itself. It may be useful to think of this process of abstraction as part of what is involved in the internalization and decoupling of temporal representations from temporal regularities in the world. Such decoupling allows representations of recurrent temporal sequences to be more arbitrary (not simply reflecting temporal regularities in the world) and flexible.

These primitive temporal frameworks have a number of key properties. First, they involve an understanding of time which is event-based or aspectual in nature. Although this early understanding of time has both perspectival and nonperspectival ingredients, the perspective on time is quite different from our adult one. We have argued that perspective here is a matter 
of keeping track of which events have been completed and which are ongoing or yet to happen, rather than a matter of grasping relations between the present time and points of time in the past and the future. The second, related, property is that such frameworks only allow events to be located with respect to recurrent sequences rather than particular times. Because of this second property, this early temporal reasoning provides a way of locating events which is fragmented into localized frames: events are located with respect to particular event sequences, rather than within one unified temporal framework which also relates events with each other that are not thematically connected.

At any rate, even though the child's reasoning at this stage may encompass quite a lot more than what happens "'here and now,' it will still be subject to a very fundamental constraint. The kinds of representations we have looked at so far are centered on the child's actual perspective in time. In other words, at this stage, children may be able to represent events happening at different times but their reasoning about these events is still constrained since they can only consider them insofar as they have a bearing on what happens "here and now.",

\section{Decentering and Early Narratives}

In the second or third year, children's narratives show evidence for the development of a new capacity to decenter, where decentering means being able to conceive of other times as affording alternative temporal perspectives. Whereas scripts are merely descriptions of the way things usually go but do not involve grasp of specific contexts other than the speech context, these narratives give a description of an event sequence which is explicitly understood to be unfolding in a different context. To a certain degree, the child is able to decenter to that other context. Take the following example of a 2year-old's fictional narrative from Antinucci \& Miller (1976, p. 186): “'One day the white sheep was going along the street. Then the white sheep said: 'The wolf, the bad wolf comes.' Then the wolf said: 'Come, come.',' This kind of narration involves a switch in perspective in that the child is not confused about what is actually happening and what is happening in the fictional setting, and she can begin the narrative at the appropriate point and work through it in a temporal sequence (Nelson, 1996). The context in which the narrated events are taken to unfold is introduced by the adverbial expression "'one day," though, in this case, this is meant to indicate a fictional rather than just a different temporal context. The switching in perspective from the actual speech context to this other context is clear from the way the tense of the characters' utterances is made appropriate to the narrative: The narrative itself is given in the past tense, but the tense of the sheep's utterance could be construed as future or present.

We think that this early kind of decentering can be understood as being analogous to the abilities involved in early pretense. Numerous authors have 
argued that in early pretense children can switch perspectives without a proper grasp of the relation between the pretend and actual perspective, namely, that they are different ways of thinking about the same object (Harris \& Kavanaugh, 1993; Jarrold, Carruthers, Smith, \& Boucher, 1994; Perner, 1991). For example, they can switch from the representation "This is a banana" to a representation "This is a telephone," and, hence, pretend that the banana is a telephone without representing the nature of relation between these representations (i.e., without representing "I am pretending of the banana 'This is a telephone', "). Our claim is that early narratives of nonpresent event sequences might also be understood in this way, and, as such, are best described as a form of decentering that involves perspective-switching rather than perspective-taking. In this sense, a child can have the ability to switch temporal perspective without being able to reason about the nature of the relation between different perspectives.

Children at this early stage of narrative production seem to have an incipient grasp of pastness, and thus of the fact that certain events they recount happened anterior to the speech context. However, there is still a decisive difference between the kind of temporal decentering they are capable of and the temporal decentering involved in mature episodic memory. Thus, in her study of monologues of the 2-year-old, Emily, Gerhardt (1989, p. 203) observed that Emily's initial use of past morphology “is indeed chosen to mark the deictic relation of pastness, but in a very restricted context. Rather than describe a single, isolated past event, she refers to events that are part of a larger event structure.' Even though the child is now able to switch perspective to things that happened in the past, her reasoning is still event-based insofar as it is only because of the interrelation between the events in the narrative that individual events can be ordered. By the same token, the child's way of locating these events in time is still localized. As Gerhardt (1989, p. 204) puts it, "there is no evidence that she can yet interrelate different event frames or freely interpolate events within these frames.' There is no reason to suppose that the child is working with a unified temporal framework that would allow events which are not thematically related to be ordered in time.

Such an ability to interrelate arbitrary events, however, seems to be one of the things that is required if one is to have a notion of the particular time at which the narrated events happened. This is not to say that one only has a notion of the particular times at which two events happened if one is actually able to order them in time. However, even if we, as adults, are unsure of the order of two remembered events, we believe there is a fact of the matter as to which happened first. And it is hard to see how a child could be said to be thinking about the events she recounts as having happened at a particular time at all unless she also grasps that there is a fact of the matter as to whether the events happened before or after certain other events she remembers. 


\section{Decentering and Self-Consciousness}

We have been providing a developmental account of a kind of temporal understanding, possession of a concept of particular times, that we believe is involved in episodic memory. However, as mentioned in the first section, other theoretical accounts of episodic memory have also claimed that episodic memory involves a particular kind of self-conscious activity (Wheeler et al., 1997). In fact, both of these properties of episodic memory may be related. This becomes clear if episodic memory is thought of as involving temporal decentering which goes beyond the perspective-switching described above. The notion of decentering in a domain has been more commonly used to describe kinds of spatial rather than temporal perspectivetaking (Piaget \& Inhelder, 1956, though see Cromer, 1971). In the spatial case, the connection between the self-conscious nature of decentering and the kind of representation of spatial domain that it involves seems clear. It could be suggested that the ability to consider multiple perspectives on a spatial layout requires a detached view of one's own perspective as one among many, and, hence, a kind of self-consciousness. Further, this ability seems to involve having a relatively sophisticated way of representing space which supports this kind of activity (see Newcombe, 1989, for a review of this research). Once episodic memory is viewed as an activity involving perspective-taking or decentering in time, a similar connection can be made between the kind of self-consciousness and the way of representing time that it involves. A number of theorists have also discussed the role of selfconsciousness in their accounts of autobiographical memory development, although they have not connected this with temporal understanding (Fivush, Haden, \& Adam, 1995; Howe \& Courage, 1997). However, since these theorists differ markedly from each other in their conceptions of autobiographical memory, the descriptions they provide of such self-consciousness differ in terms of whether they are more sophisticated than the self-consciousness we will claim is involved in episodic memory (for example, Fivush's, 1997, description can be contrasted with that of Howe \& Courage, 1993).

Spatial decentering tasks measure children's ability to comprehend perspectival representations of an array of objects as seen from an arbitrary vantage point which differs from the one they actually occupy. Children who succeed in such tasks can be said not only to be able to switch between perspectives, but also to have a conception of those perspectives as perspectives onto the same spatial reality, and an understanding of the systematic relationships that obtain between these perspectives in virtue of this fact. This kind of understanding, which Flavell (e.g., Flavell, Green, \& Flavell, 1989) has labeled Level 2 perspective-taking, has been described as mentalistic (Perner, 1991), since part of what it involves is an understanding of the perspectival nature of visual experience itself and how it is determined by one's position relative to a spatial array. 
We wish to suggest that temporal decentering, if it is to be more than the perspective-switching described above, must similarly involve a conception of temporal perspectives as perspectives onto the same temporal reality and an understanding of the systematic relations that obtain between different temporal perspectives in virtue of this fact. Understanding that there can be multiple temporal perspectives on the same event, for example, involves being able to reason that a current ongoing event will be in the past from the perspective of subsequent days and was in the future from the perspective of previous days. Thus, just as Level 2 spatial perspective-taking involves understanding that how an object looks is dependent on one's perspective, its temporal equivalent involves understanding that that the way one is thinking about events is dependent on one's perspective in time. Just as in the spatial case, temporal perspective-taking involves mentalizing abilities. Specifically, it could be argued that it involves the ability to conceive of oneself as the possessor of mental states which depend on one's temporal perspective. This can be contrasted with more primitive kinds of self-consciousness, which do not yet involve thinking of oneself as a possessor of mental states, such as those measured by mirror self-recognition.

In emphasizing the role of mentalizing here, our account is related to that of Perner, who has argued that such abilities are necessary for episodic memory. There is, however, a second feature to the type of self-consciousness involved in episodic memory, which is not yet accommodated by the mere notion of mentalizing. It seems that, in the temporal case, what underpins the grasp of the systematic relations between different temporal perspectives is an awareness of oneself as the occupier of these different perspectives, i.e., of oneself as temporally extended (Neisser, 1991; Povinelli et al., 1996; Povinelli \& Simon, 1998). Whereas spatial decentering of the kind we have described can be understood as an ability to construct alternative perspectives on the basis of the perceptual information currently available (as perspectives one could, but need not occupy), temporal perspective-taking is only possible because one has actually occupied other temporal perspectives and is able to conceive of them as perspectives that one has occupied (see Campbell, 1994, 1997, for more detailed analyses). In other words, temporal perspective-taking or decentering, as we have described it, is associated with a grasp of the fact that there were previous points in time at which one's temporal perspective on events was quite different but one's own nonetheless.

\section{Future Directions for Research}

A new account of the development of children's understanding of time has been provided, one that links such understanding with memory development. Most previous research on temporal understanding in children has been in the Piagetian tradition (see Levin, 1992, for a review of this research). That tradition focuses on a specific and sophisticated kind of temporal reasoning, namely, grasp of the relationships between speed, distance, and duration. 
There has been little empirical research on children's concepts of time outside of that tradition, perhaps because it is not straightforward to generate appropriate methodologies for use with young children. Although it is difficult to assess children's concepts of time directly, we finish by showing how our account provides a way of interpreting a variety of existing empirical findings in terms of children's understanding of time, and how it can also be used to generate some directions for future research.

Deferred imitation. We have argued that although deferred imitation studies demonstrate that young children can represent event sequences, early in development, such sequences may not yet function as temporal frameworks. A clear prediction of this claim is that infants may have difficulty using such representations flexibly as a means of representing the location of novel events. Most of the existing deferred imitation studies on the flexible use of event representations have varied the props provided for use in behavioral reenactment. For example, Bauer and Dow (1994) have shown that children aged between 16 and 20 months will reenact previously demonstrated event sequences, even when provided with an entirely novel set of props (see also Bauer \& Fivush, 1992; Fivush, Kuebli, \& Clubb, 1992). We agree with Bauer and Dow that such findings demonstrate some degree of generalization of event representations: Children must have sufficiently general descriptions or representations of the event sequence such that various objects could be used to carry out the actions specified in the sequence. However, demonstrations of such generalization fall short of showing that such event representations can be used as frameworks to provide locations for novel elements. To show this, the components (i.e., the target actions) of the demonstrated sequences themselves must be varied rather than the props. Although studies of 3- and 4-year-olds' recall of stories or events have examined the effects of varying such components (e.g., Farrar \& Goodman, 1990; Fivush et al., 1992; Kuebli \& Fivush, 1994), we are not aware of any deferred imitation studies with infants which have done so. Our suggestion is that, if novel components are inserted into an event sequence, early in development children may not show evidence of using a pre-existing temporal representation as a framework to represent their location. Rather, they may simply form a separate new representation of the presented event sequence or ignore the novel component.

With development, children should become capable of applying existing event sequences in situations in which not all the original elements are present, or in which novel elements are added. This development may have wideranging implications for children's performance on tasks requiring the recruitment or modification of a previously acquired action sequence. For example, Zelazo, Reznick, and Spinazzola (1998) found that even 2-year-olds have difficulty with multistep multilocation tasks in which one step of a previously acquired action sequence must be modified to successfully retrieve a reward. Although performance on this task is determined by a num- 
ber of other factors, such as levels of response inhibition, Zelazo et al. pointed out that one requirement of the task is "analyzing practiced behavioral routines into separate steps and modifying an intermediate step", (p. 212). Such flexible use of event representations may develop later than the ability to accurately reproduce event sequences.

Localized temporal frameworks. It has been argued that, even by around 2 or 3 years when children are using sequential event representations as temporal frameworks, such frameworks are limited in that they are localized. In other words, there is no grasp of the systematic temporal relations that obtain between thematically unrelated events. This account makes a number of predictions with regard to children's memory. First, although early memory narratives may describe the particular components of an event in the appropriate temporal sequence, such sequences may not be temporally linked with other events which happened on different occasions. This lack of a grasp of the temporal relations between occurrences at different times should be reflected in children's early uses of temporal terms and tensed verb forms. Thus, there should be a developmental stage in which such linguistic forms are used correctly to describe the relations between components of a given event sequence but not yet used to mark the temporal relations between different events.

Since, at this stage, children do not grasp the temporal relations between arbitrary points in time, they would be expected to perform poorly on memory tasks which explicitly require judgments about the temporal order of different life events. In fact, in a series of studies, Friedman has assessed children's memory and understanding of such temporal relations. Typically, he has used relative recency judgment tasks in which children are asked of two life events "Which one happened a long time ago and which one happened a short time ago?' (Friedman, 1991, 1992; Friedman, Gardner, \& Zubin, 1995; Friedman \& Kemp, 1998). Friedman has found that, by 4 years of age, children are above chance at making such relative recency judgments for some kinds of events. His findings suggest that, at least by this age, children can think about the temporal relations between episodes, rather than simply being able to sequence the components of a single episode. However, although he has included children as young as 2 and 3 years in some of his studies, he has not reported on whether performance on such tasks improves markedly during the preschool years (typically, he has compared a preschool group with an older group). Further studies on the ability to judge the relative recency of events could focus in more detail on how such abilities develop in the early years.

Temporal decentering. We have described the emergence of episodic memory as involving temporal decentering, and there is some evidence to suggest that, by 4 or 5 years, this ability is intact. Although it is not straightforward to assess this ability empirically, Cromer (1971) has carried out a study using a task he has described as measuring temporal decentering. His 
task can be interpreted as requiring children to reason about other temporal perspectives, while having minimal demands on memory. Using a picturestory format, Cromer examined when children were able to match descriptions of events given in a particular tense with the point in time in which such descriptions were accurate. For example, the sentence "I will see the horses" should have been matched with a point in time before the story character saw the horses. Cromer argued that such matching required children to decenter and take up different temporal perspectives on the story events. The youngest children in Cromer's study were 5 years of age, and such children showed some evidence of decentering. A further study which used a simplified version of Cromer's task found good performance in 5year-olds (Russell, McCormack, Stow, \& Parker, 1998).

Although future studies could examine such abilities at younger ages, the heavily linguistic nature of Cromer's task makes it unsuitable for very young children. Also, it is questionable whether this task can be thought of as measuring children's ability to decenter to past events in their own lives, since it involves fictional events. In fact, recent research using a quite different paradigm suggests that 3 -year-olds may still have difficulties in reasoning about other temporal perspectives that they have occupied. Povinelli et al. (1996) have found that preschoolers fail a delayed self-recognition task, in which they are shown a video or a photograph of a sticker being placed on their heads at an earlier time. Although Povinelli et al. argued that their tasks assess children's self concept, they may also measure a general ability to engage in temporal decentering and reason about the relationships between past and present temporal perspectives. Indeed, Zelazo, Sommerville, and Nichols (in press) have shown that 3-year-olds seem to have more global problems reasoning about representations of past situations and using information from such representations to guide their current behavior. Future research could examine the relationship between performance on such temporal perspective-taking tasks and children's memory (e.g., their ability to make relative recency judgments about the relationships between past events). Indeed, one study has already found such a relationship: Skene (1996) found that performance on a delayed recognition task was correlated with the ability to make judgments about the relative order of some events, even when age was partialed out.

Temporal decentering and memory sharing. Once the development of episodic memory is described in terms of the emergence of temporal decentering, it seems clear that memory sharing may play a crucial role in its development (e.g., Fivush \& Reese, 1991; Hudson, 1990). Just as the kind of perspective-switching that occurs in early pretend play first occurs in a social setting, so may the kind of perspective-switching that occurs in early memory retrieval. Indeed, it may be adults who normally (but not always, as Emily's monologues demonstrate; Nelson, 1989) initiate this kind of perspective-switching by prompting the child with cues about specific past 
events. Through the experience of sharing memories, such as different memories of the same past event, children may then begin to conceive of such memories as involving alternative perspectives in time that they once occupied. In this respect, our account is compatible with a variety of findings which suggest that social sharing of memories is important in the development of memory narratives (Haden, Haine, \& Fivush, 1997; Hudson, 1990; Reese, Haden, \& Fivush, 1993). Further, we have described such perspective-taking in time as self-conscious since it has a mentalistic component, and, indeed, a recent study by Welch-Ross (1997) has found relationships between mentalizing abilities and children's engagement in talk about the past with their parents. Since we view perspective-taking in time as involving a particular kind of temporal understanding (a conception of particular past times), social sharing of memories and mentalizing can thus be thought of as being important for the development of children's concepts of time. Therefore, we might expect to see relationships between children's social experiences, their mentalizing abilities, and their ability to reason about the relationships between points in time.

\section{REFERENCES}

Aktar, N., \& Tomasello, M. (1996). Two-year-olds learn words for absent objects and actions. British Journal of Developmental Psychology, 14, 79-93.

Antinucci, F., \& Miller, R. (1976). How children talk about what happened. Journal of Child Language, 3, 167-189.

Bauer, P. J. (1995). Recalling past events: From infancy to early childhood. Annals of Child Development, 11, 25-71.

Bauer, P. J., \& Dow, G. A. (1994). Episodic memory in 16- and 20-month-old children: Specifics are generalized but not forgotten. Developmental Psychology, 30, 403-417.

Bauer, P. J., \& Fivush, R. (1992). Constructing event representations: Building on a foundation of variations and enabling relations. Cognitive Development, 7, 381-401.

Bauer, P. J., \& Mandler, J. M. (1989). One thing follows another: Effects of temporal structure on 1- to 2-year-olds' recall of events. Developmental Psychology, 25, 197-206.

Bauer, P. J., \& Mandler, J. M. (1992). Putting the horse before the cart: The use of temporal order in recall of events by one-year-old children. Developmental Psychology, 28, 441452.

Bloom, L., \& Harner, L. (1989). On the developmental contour of child language: A reply to Smith \& Weist. Journal of Child Language, 16, 207-216.

Bloom, L., Lifter, K., \& Hafitz, J. (1980). Semantics of verbs and the development of verb inflection in child language. Language, 56, 386-412.

Bronckhart, J. P., \& Sinclair, H. (1973). Time, tense and aspect. Cognition, 2, 107-130.

Brown, G. D. A., \& Vousden, J. I. (1998). Adaptive analysis of sequential behavior: Oscillators as rational mechanisms. In M. Oaksford \& N. Chater (Eds.), Rational models of cognition (pp. 165-193). Oxford, UK: Oxford Univ. Press.

Burt, C. D. B. (1992). Retrieval characteristics of autobiographical memories: Event and date information. Applied Cognitive Psychology, 6, 389-404.

Campbell, J. (1994). Past, space, and self. Cambridge, MA: MIT Press. 
Campbell, J. (1997). The structure of time in autobiographical memory. European Journal of Philosophy, 5, 105-118.

Comrie, B. (1985). Tense. Cambridge, UK: Cambridge Univ. Press.

Cromer, R. F. (1971). The development of the ability to decenter in time. British Journal of Psychology, 62, 353-365.

Davies, G. M., \& Thomson, D. M. (Eds.) (1988). Memory in context: Context in memory. Chichester, UK: John Wiley \& Sons.

Eilan, N., McCarthy, R., \& Brewer, B. (Eds.) (1993). Spatial representation: Problems in philosophy and psychology. Oxford, UK: Oxford Univ. Press.

Farrar, M. J., \& Goodman, G. S. (1990). Developmental differences in the relation between scripts and episodic memory: Do they exist? In R. Fivush \& J. A. Hudson (Eds.), Knowing and remembering in young children (pp. 30-64). Cambridge, UK: Cambridge Univ. Press.

Fivush, R. (1984). Learning about school: The development of kindergartener's school scripts. Child Development, 55, 1697-1709.

Fivush, R. (1997). A self in time. Paper presented at the biennial meeting of the Society for Research in Child Development, Washington, DC.

Fivush, R., Haden, C., \& Adam, S. (1995). Structure and coherence of preschoolers' personal narratives over time: Implications for childhood amnesia. Journal of Experimental Child Psychology, 60, 32-56.

Fivush, R., \& Hamond, N. R. (1990). Autobiographical memory across the preschool years: Toward reconceptualizing childhood amnesia. In R. Fivush \& J. A. Hudson (Eds.), Knowing and remembering in young children (pp. 223-248). Cambridge, UK: Cambridge Univ. Press.

Fivush, R., Hudson, J. A., \& Nelson, K. (1984). Children's long-term memory for a novel event: An exploratory study. Merrill-Palmer Quarterly, 30, 303-316.

Fivush, R., Kuebli, J., \& Clubb, P. A. (1992). The structure of events and event representations: Developmental analysis. Child Development, 63, 188-201.

Fivush, R., \& Reese, E. (1991). The social construction of autobiographical memory. In M. A. Conway, D. C. Rubin, H. Spinnler, \& W. A. Wagenaar (Eds.), Theoretical perspectives on autobiographical memory (pp. 115-132). Dordrecht, The Netherlands: Kluwer.

Flavell, J. H., Green, F. L., \& Flavell, E. R. (1989). Young children's ability to differentiate appearance-reality and Level 2 perspectives in the tactile modality. Child Development, 60, 201-213.

Friedman, W. J. (1987). A follow-up to "Scale effects in memory for time of events"': The earthquake study. Memory \& Cognition, 15, 518-520.

Friedman, W. J. (1990). About time: Inventing the fourth dimension. Cambridge, MA: MIT Press.

Friedman, W. J. (1991). The development of children's memory for the time of past events. Child Development, 62, 139-155.

Friedman, W. J. (1992). Children's time memory: The development of a differentiated past. Cognitive Development, 7, 171-187.

Friedman, W. J. (1993). Memory for the time of past events. Psychological Bulletin, 113, 4466.

Friedman, W. J., Gardner, A. G., \& Zubin, N. R. E. (1995). Children's comparisons of the recency of 2 events from the past year. Child Development, 66, 970-983.

Friedman, W. J., \& Kemp, S. (1998). The effects of elapsed time and retrieval on young children's judgments of the temporal distances of past events. Cognitive Development, 13, 335-367. 
Gallistel, C. R. (1990). The organization of learning. Cambridge, MA: MIT Press.

Gerhardt, J. (1989). Monologue as a speech genre. In K. Nelson (Ed.), Narratives from the crib. Cambridge, MA: Harvard Univ. Press.

Guenther, R. K., \& Linton, M. (1975). Mechanisms of temporal coding. Journal of Experimental Psychology: Human Learning and Memory, 97, 220-229.

Hasher, L., \& Zacks, R. T. (1979). Automatic and effortful processes in memory. Journal of Experimental Psychology: General, 108, 356-388.

Harris, P. L., \& Kavanaugh, R. D. (1993). Young children's understanding of pretense. Monographs of the Society for Research in Child Development, 58 (1, Serial No. 231).

Haden, C., Haine, R., \& Fivush, R. (1997). Developing narrative structure in parent-child conversations about the past. Developmental Psychology, 33, 295-307.

Hintzman, D. L., Block, R. A., \& Summers, J. J. (1973). Contextual associations and memory for serial position. Journal of Experimental Psychology, 97, 220-229.

Howe, M. L., \& Courage, M. L. (1993). On resolving the enigma of infantile amnesia. Psychological Bulletin, 113, 305-326.

Howe, M. L., \& Courage, M. L. (1997). The emergence and early development of autobiographical memory. Psychological Review, 104, 499-523.

Hudson, J. A. (1990). The emergence of autobiographical memory in mother-child conversation. In R. Fivush \& J. A. Hudson (Eds.), Knowing and remembering in young children (pp. 166-196). Cambridge, UK: Cambridge Univ. Press.

Hudson, J. A., \& Nelson, K. (1986). Repeated encounters of a similar kind: Effects of familiarity on children's autobiographical memory. Cognitive Development, 1, 253-271.

Huttenlocher, J., Hedges, L., \& Prohaska, V. (1988). Hierarchical organization in ordered domains: Estimating the dates of events. Psychological Review, 95, 471-484.

Jarrold, C., Carruthers, P., Smith, P., \& Boucher, J. (1994). Pretend play: Is it metarepresentational? Mind \& Language, 9, 445-468.

Kihlstrom, J. F., \& Harackiewicz, J. M. (1982). The earliest recollection: A new survey. Journal of Personality, 50, 134-148.

Kuebli, J., \& Fivush, R. (1994). Children's representations and recall of event alternatives. Journal of Experimental Child Psychology, 58, 25-45.

Levin, I. (1992). The development of the concept of time in children: An integrative model. In F. Macar, V. Pouthas, \& W. J. Friedman (Eds.), Time, action, and cognition: Towards bridging the gap (pp. 13-32). Dordrecht, The Netherlands: Kluwer.

McTaggart, J. E. (1927). The nature of existence. Vol. II. Cambridge, UK: Cambridge Univ. Press.

Meltzoff, A. N. (1990). Towards a developmental cognitive science: The implications of crossmodal matching and imitation for the development of representation and memory in infancy. In A. Diamond (Ed.), Annals of the New York Academy of Science: Vol. 608. The development and neural bases of higher cognitive functions (pp. 1-37). New York: New York Academy of Science.

Nairne, J. S. (1991). Positional uncertainty in long-term memory. Memory \& Cognition, 19, $332-340$.

Naveh-Benjamin, M. (1990). Coding of temporal order information: An automatic process? Journal of Experimental Psychology: Learning, Memory, and Cognition, 16, 117-126.

Neisser, U. (1991). Five kinds of self-knowledge. In D. Kolak \& R. Martin (Eds.), Self and identity: Contemporary philosophical issues (pp. 386-406). Toronto, Canada: Collier Macmillan. 
Nelson, K. (1986). Event knowledge: Structure and function in development. Hillsdale, NJ: Erlbaum.

Nelson, K. (1989). Narratives from the crib. Cambridge, MA: Harvard Univ. Press.

Nelson, K. (1990). Remembering, forgetting and childhood amnesia. In R. Fivush \& J. A. Hudson (Eds.), Knowing and remembering in young children (pp. 223-248). Cambridge, UK: Cambridge Univ. Press.

Nelson, K. (1996). Language in cognitive development: Emergence of the mediated mind. Cambridge, UK: Cambridge Univ. Press.

Nelson, K., \& Hudson, J. A. (1988). Scripts and memory: Functional relationships in development. In F. E. Weinert \& M. Perlmutter (Eds.), Memory development: Universal changes and individual differences (pp. 147-167). Hillsdale, NJ: Erlbaum.

Nelson, K., \& Ross, G. (1980). The generalities and specifics of long-term memory in infants and young children. In M. Perlmutter (Ed.), New directions for child development: Vol. 10. Children's memory (pp. 87-101). San Francisco: Jossey-Bass.

Newcombe, N. (1989). The development of spatial perspective taking. Advances in Child Development and Behavior, 22, 203-247.

O'Keefe, J., \& Nadel, L. (1978). The hippocampus as a cognitive map. Oxford, UK: Oxford Univ. Press.

Perner, J. (1990). Experiential awareness in children's episodic memory. In W. Schneider \& F. E. Weinert (Eds.), Interactions among aptitudes, strategies, and knowledge in cognitive performance (pp. 3-11). New York: Springer Verlag.

Perner, J. (1991). Understanding the representational mind. Cambridge, MA: MIT Press.

Perner, J. (in press). Memory and theory of mind. In E. Tulving \& F. I. M. Craik (Eds.), The Oxford handbook of memory. Oxford, UK: Oxford Univ. Press.

Perner, J., \& Ruffman, T. (1995). Episodic memory and autonoetic consciousness: Developmental evidence and a theory of childhood amnesia. Journal of Experimental Child Psychology, 59, 516-548.

Piaget, J., \& Inhelder, B. (1956). The child's conception of space. London, UK: Routledge \& Kegan Paul.

Pick, H. L., Jr., \& Lockman, J. J. (1981). From frames of reference to spatial representation. In L. S. Liben, A. H. Patterson, \& N. Newcombe (Eds.), Spatial representation and behavior across the lifespan (pp. 39-61). New York: Academic Press.

Povinelli, D. J., Landau, K. R., \& Perilloux, H. K. (1996). Self-recognition in young children using delayed versus live feedback: Evidence of a developmental asynchrony. Child Development, 67, 1540-1554.

Povinelli, D. J., \& Simon, B. B. (1998). Young children's understanding of briefly versus extremely delayed images of the self: Emergence of the autobiographical stance. Developmental Psychology, 34, 188-194.

Ratner, H. H., Smith, B. S., \& Padgett, R. J. (1990). Children's organization of events and event memories. In R. Fivush \& J. A. Hudson (Eds.), Knowing and remembering in young children (pp. 65-93). Cambridge, UK: Cambridge Univ. Press.

Reese, E., Haden, C. A., \& Fivush, R. (1993). Mother-child conversations about the past: Relationships of style and memory over time. Cognitive Development, 8, 403-430.

Reichenbach, H. (1947). Elements of symbolic logic. New York: Macmillan.

Rispoli, M., \& Bloom, L. (1985). Incomplete and continuing: Theoretical issues in the acquisition of tense and aspect. Journal of Child Language, 12, 471-474.

Rovee-Collier, C. (1997). Dissociations in infant memory: Rethinking the development of implicit and explicit memory. Psychological Review, 104, 467-498. 
Russell, J., McCormack, T., Stow, I., \& Parker, A. (1998). The development of spatial and temporal decentering in young children. Manuscript in preparation, University of Cambridge, UK.

Sachs, J. (1983). Talking about the there and then: The emergence of displaced reference in parent-child discourse. In K. E. Nelson (Ed.), Children's language (Vol. 4, pp. 1-28). Hillsdale, NJ: Erlbaum.

Schank, R. C., \& Abelson, R. P. (1977). Scripts, plans, goals, and understanding. Hillsdale, NJ: Erlbaum.

Skene, K. M. L. (1996). Self-awareness in preschool children: The development of temporal self-continuity. Unpublished Masters thesis, Dalhousie University, Halifax, Canada.

Smith, C. S. (1980). The acquisition of time talk: Relations between child and adult grammars. Journal of Child Language, 7, 263-278.

Smith, C. S., \& Weist, R. M. (1987). On the temporal contour of child language: A reply to Rispoli and Bloom. Journal of Child Language, 14, 387-392.

Tomasello, M., \& Kruger, A. C. (1992). Joint attention on actions: Acquiring verbs in ostensive and non-ostensive contexts. Journal of Child Language, 19, 311-333.

Tulving, E. (1972). Episodic and semantic memory. In E. Tulving \& W. Donaldson (Eds.), Organization of memory (pp. 381-403). New York: Academic Press.

Tulving, E. (1983). Elements of episodic memory. Oxford, UK: Oxford Univ. Press.

Tulving, E. (1985). Memory and consciousness. Canadian Psychology, 25, 1-12.

Vendler, Z. (1957). Verbs and times. Philosophical Review, 66, 143-160.

Wagenaar, W. A. (1986). My memory: A study of autobiographical memory over six years. Cognitive Psychology, 18, 225-252.

Weist, R. M. (1986). Tense and aspect. In P. Fletcher \& M. Garman (Eds.), Language acquisition: Studies in first language development (2nd ed., pp. 356-374). Cambridge, UK: Cambridge Univ. Press.

Weist, R. M. (1989). Time concepts in language and thought: Filling the Piagetian void from two to five years. In I. Levin \& D. Zakay (Eds.), Time and human cognition: A life-span perspective (pp. 63-118). Amsterdam, The Netherlands: Elsevier.

Welch-Ross, M. K. (1997). Mother-child participation in conversation about the past: Relationships to preschoolers' theory of mind. Developmental Psychology, 33, 618-629.

Wetzler, S. E., \& Sweeny, J. A. (1986). Childhood amnesia: An empirical demonstration. In D. C. Rubin (Ed.), Autobiographical memory (pp. 191-201). Cambridge, UK: Cambridge Univ. Press.

Wheeler, M. A., Stuss, D. T., \& Tulving, E. (1997). Toward a theory of episodic memory: The frontal lobes and autonoetic consciousness. Psychological Bulletin, 121, 331-354.

Zacks, R. T., Hasher, L., Alba, J. W., Sanft, H., \& Rose, K. C. (1984). Is temporal-order encoded automatically? Memory \& Cognition, 12, 387-394.

Zelazo, P. D., Reznick, J. S., \& Spinazzola, J. (1998). Representational flexibility and response control in a multistep multilocation search task. Developmental Psychology, 34, 203214.

Zelazo, P. D., Sommerville, J., \& Nicholas, S. (in press). Age-related changes in children's use of external representations. Developmental Psychology.

Received: July 21, 1998; revised: September 28, 1998 